\title{
PRENATAL DEVELOPMENT OF RETINOCOLLICULAR PROJECTIONS IN THE CAT: AN ANTEROGRADE TRACER TRANSPORT STUDY ${ }^{1}$
}

\author{
ROBERT W. WILLIAMS ${ }^{2}$ AND LEO M. CHALUPA
}

Department of Psychology and Physiology Graduate Group, University of California, Davis, California 95616

Received July 27, 1981; Revised December 14, 1981; Accepted December 14, 1981

\begin{abstract}
The retinal projection to the superior colliculus of the cat was examined at four gestational ages, embryonic days $38,46,56$, and 61 , using the anterograde transport of horseradish peroxidase and tritiated leucine. Gestation in the cat averages 65 days. By the 38th day of gestation (E38), the anlage of the entire superior colliculus, both ipsilateral and contralateral to an injection, was labeled intensely. The peroxidase label had an extremely coarse grained texture. As late as E46, the ipsilateral retinal projection extended to the presumed caudal border of the colliculus, while by E56, as in the mature cat, the ipsilateral terminal field was largely excluded from the rostral and caudal tectal poles. The contralateral terminal field at E56, as in younger fetal material, extended across the entire tectal mantle. By E61, clear gaps of label were observed in the contralateral stratum griseum superficiale. At this age, patches or bands of label were accentuated on the ipsilateral side. In double labeled tissue, it could be demonstrated that the ipsilateral patches corresponded quite closely to the gaps in the contralaterally derived label. Thus, a few days before birth, the retinal projection to the superior colliculus has a pattern which resembles that of the adult.
\end{abstract}

During the last decade, the advent of axoplasmic transport tracing methods has provided a wealth of data on developing retinofugal projections in a variety of vertebrates ranging from the frog (Currie and Cowan, 1975) to the monkey (Rakic, 1977a). Recent work has shown that the initial distribution of retinal ganglion cell axons in fetal and neonatal mammals is more diffuse and extensive than can be demonstrated in the adult (Rakic, 1977a; Cavalcante and Rocha-Miranda, 1978; Frost et al., 1979; Land and Lund, 1979; K. J. Sanderson, P. G. Dixon, and L. J. Pearson, submitted for publication).

Remarkably little is known about the in utero development of the feline visual system. With the exception of the work of Cragg (1975), Anker (1977), and Shatz and her colleagues (Shatz and DiBerardino, 1980; Kliot and Shatz, 1981), the genesis of retinal projections has not been examined. The predominant position of the cat in research involving the postnatal maturation of visual function warrants a considerably more complete description of the formation of this species' visual system.

\footnotetext{
${ }^{1}$ This research was supported in part by the National Institutes of Health under Grant 532 GM 07416. We thank Dr. Charles J. Sedgwick, Department of Veterinary Medicine, University of California, Davis, for his guidance and assistance in the surgical procedures.

${ }^{2}$ To whom correspondence should be addressed at Department of Psychology, University of California, Davis, CA 95616.
}

Our work has been directed at establishing the normal sequence of events leading to the formation of the mature retinocollicular projection. The tectal anlage does not undergo substantial rotation during development as does, for example, the dorsal lateral geniculate nucleus (DLGn) (Rakic, 1977b; Kalil, 1978; Shatz and DiBerardino, 1980). This simplifies the analysis and reconstruction of the distribution of axonal label and makes a comparison between animals of different gestational ages relatively straightforward. In addition, an excellent background for the developmental work is provided by the substantial number of studies which have examined retinocollicular connections in the adult cat using a variety of anatomical techniques (Laties and Sprague, 1966; Sterling, 1973; Kelly and Gilbert, 1975; Graybiel, 1975, 1976; Harting and Guillery, 1976; Magalhães-Castro et al., 1976; Wässle and Illing, 1980; Bowling and Michael, 1980; Behan, 1981; Mize, 1981).

We have found that in the cat, as in the monkey (Rakic, 1977a), the retinal projections to the superior colliculus of fetal animals are more widespread than those demonstrated after parturition. The mature pattern of termination appears to be sculpted from a profuse prenatal projection field by the selective retraction and partial segregation of crossed and uncrossed retinal efferents. The details of this reformation of retinal input to the superior colliculus are the main emphasis of this 
paper. Abstracts summarizing some of our findings have been published recently (Williams and Chalupa, 1980, 1981).

\section{Materials and Methods}

Timed pregnancies were obtained by exposing an estrous female to a potent male cat for $24 \mathrm{hr}$. To ensure that the female was receptive, a number of matings were observed. The end of the 24-hr exposure period marked the beginning of embryonic day 1 (E1). This method of timing conception is only accurate to within I day. Gestation in the domestic cat has a duration ranging from 62 to 67 days.

Anesthesia was induced in the pregnant cat with a $4 \%$ halothane vapor in oxygen. Following intubation and during the entire surgical procedure, the halothane concentration was maintained at 1.0 to $1.5 \%$. A midline abdominal incision was made under aseptic conditions and the uterine horns were withdrawn in turn. Each fetal head was located by palpation and a small longitudinal incision of the uterus was made to expose the head. Membranes and skin overlying the eye were parted. Each eye then received an intravitreal injection of either horseradish peroxidase (HRP) or $\left[{ }^{3} \mathbf{H}\right]$ leucine. HRP was diluted in distilled water to a concentration of $30 \%$. The peroxidase injections ranged from $5 \mu \mathrm{l}$ for the youngest fetuses up to $20 \mu \mathrm{l}$ for perinatal animals. Injections of $\left[{ }^{3} \mathrm{H}\right]$ leucine (specific activity, $57 \mathrm{Ci} / \mathrm{mmol}$ ) ranged from $20 \mu \mathrm{Ci}$ in $0.4 \mu \mathrm{l}$ to $100 \mu \mathrm{Ci}$ in $2.0 \mu \mathrm{l}$, again varying with age. Due to the large volume of the peroxidase injections, leakage around the site of puncture was common. For this reason, we are unable to specify the exact quantity of peroxidase delivered into the vitreous. The amount spilled was frequently sufficient to label substantial numbers of neurons innervating extrinsic ocular muscle. The injections were made using a Hamilton microliter syringe fitted with a 26 gauge needle or with a fine tipped glass pipette equipped with a plunger. To avoid penetrating the retina, the insertion site was made far anterior, roughly at the site of the ciliary body.

Following completion of the injections, the uterine and abdominal incisions were closed with absorbable suture, and anesthesia was discontinued. The female was usually alert within $20 \mathrm{~min}$ after surgery. Approximately $24 \mathrm{hr}$ later, the cat was reanesthetized, and the fetuses were delivered by cesarean section. Fetuses were perfused immediately by transcardial infusion of physiological saline, followed by a phosphate-buffered $2.5 \%$ glutaraldehyde, $1.0 \%$ paraformaldehyde solution, and finally $10 \%$ sucrose in phosphate buffer. The mother's incisions were closed and anesthesia was terminated.

Less than $2 \mathrm{hr}$ after fixation of the fetuses, the eyes and brains were removed, weighed, and photographed. The brains were immersed in a $20 \%$ sucrose solution for $24 \mathrm{hr}$, blocked in the frontal plane, and cut frozen at a thickness of $40 \mu \mathrm{m}$ using a sliding microtome. All sections were saved in phosphate buffer and alternate sections were mounted for conventional autoradiographic processing (Hendrickson and Edwards, 1978). Tissue was cleared in xylene, air-dried in a humid dust-free environment, and then dipped in Kodak NTB-2 emulsion. The sections were stored at $4^{\circ} \mathrm{C}$ for 8 weeks and developed in Kodak D-19. The remaining tissue was reacted to dem- onstrate the presence of the peroxidase enzyme using the chromogen tetramethyl benzidine (TMB) (Mesulam, 1978). Every 10th section reacted for peroxidase histochemistry also was counterstained with cresyl violet.

\section{Results}

The midbrain of the fetal cat is a conspicuous and relatively large structure which extends $6.0 \mathrm{~mm}$ in the rostrocaudal axis by the 5th week of gestation (Fig. 1). The tectal cleft, setting off the superior from the inferior collicular anlagen, is not easily distinguished at this age. However, if the most caudal extension of retinal ganglion cell axons is considered to mark this boundary, then, as early as E38, the superior colliculus extends $2.7 \pm 0.2$ $\mathrm{mm}$. A comparable figure for the mature superior colliculus is $5.0 \pm 0.5 \mathrm{~mm}$. At E38 and E46, no demarcation can be made between the rostral collicular margin and the pretectum (Fig. 2). By E56, the pretectal nuclei, especially the nucleus of the optic tract and the pretectal olivary nucleus, can be differentiated from the more dorsal fasciculi of retinal efferents (R. W. Williams and L. M. Chalupa, unpublished observations), and at the rostral collicular margin, a portion of these efferents becomes capped dorsally by the superficial gray. At this age, then, the anterior border of the superior colliculus is well defined.

Injections of tracer substances were made into the eyes of 36 fetal cats ranging in age from E30 to E61. The results presented in this paper are based on the 10 fetuses (see Table I) in which there was no retinal damage and in which fixation by perfusion was successful so that axonal transport to the superior colliculus could be demonstrated for at least one of the tracers. All photomicrographs and photomontages are identified both by the age and the number of the individual cat, in parentheses, from which the material was obtained.

As early as E30, a prominent optic chiasm is present (Anker, 1977; R. W. Williams, unpublished observation), and it is therefore probable that optic axons have penetrated the roof of the mesencephalon at least a few days before the end of the 1st month of gestation. Shatz and DiBerardino (1980) have demonstrated a bilateral projection to the cat diencephalon as early as E32, and at this age, Shatz (personal communication) has noted the presence of a weak contralateral retinocollicular projection.

E38. In our material, a bilateral projection to the mantle of the superior colliculus anlage could be demonstrated with both tracers as early as E38. The distribution of peroxidase label in one of the three successful E38 fetuses is shown in Figure 2. A gradient of the density of the TMB chromogen through the depth of the tectal plate is evident. This plate is characterized by a very high cell population density with a maximum thickness of $300 \mu \mathrm{m}$. The intense label ends abruptly at the ventral margin of the plate. Medial and lateral portions of the contralateral colliculus were labeled more heavily than was the central band. This erosion of label toward the middle was even more marked on the ipsilateral side (Fig. 2, right side). In spite of these gradients in the density of label, the entire rostrocaudal extent of the contralateral tectal plate was labeled heavily.

The most remarkable feature of peroxidase labeling at 

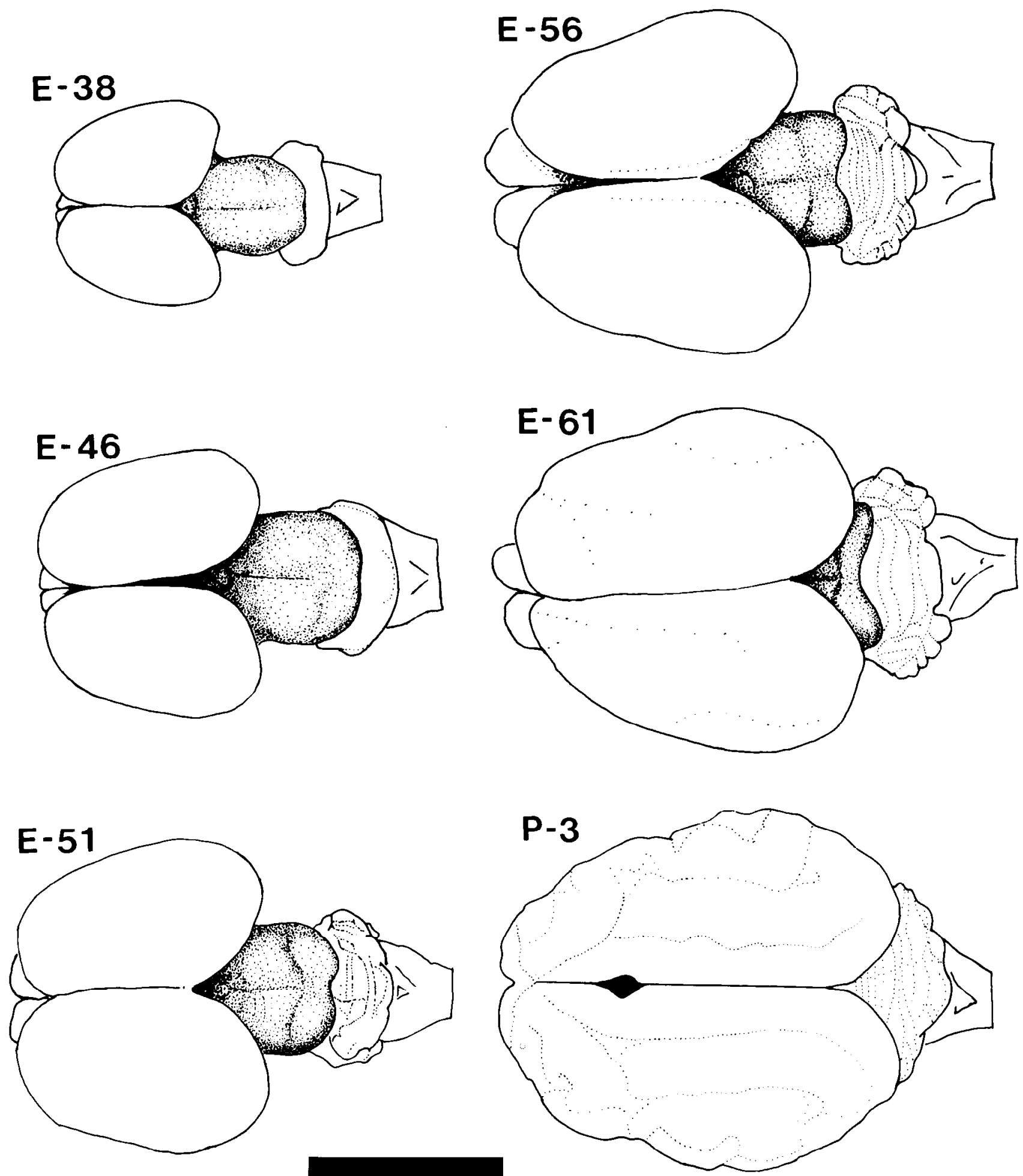

Figure 1. Drawings, bascd on photographs, of the dorsal view of the fetal and early postnatal cat brain. The mesencephalon, including the superior and inferior colliculi, is clearly visible as the shaded portion of the drawings of the fetal brains. This drawing includes an E51 fetus not otherwise covered under "Results." Calibration bar, $1 \mathrm{~cm}$.

E38 was its extremely coarse grained texture (Fig. $3 A$ ). In coronal sections through the midbrain, the label was made up entirely of large clumps of polymerized TMB chromogen. This coarse label may be due to a combination of the following factors: $(i)$ the absence of fine terminal arbors, (ii) the relatively small number of retinal efferents which have penetrated the collicular mantle, and (iii) the presence of large labeled terminal varicosities or growth cones. Sections cut through the dorsal lateral geniculate nucleus (DLGn), in which axons course parallel to the plane of section, revealed the dilated axon tips characteristic of axonal extension (Fig. $3 B$ ). The ubiquily of what appear to be growth cones in the DLGn suggests that all portions of this nucleus were being 
TABLE I

Summary data on fetuses used in this study

\begin{tabular}{lcccc}
\hline & \multicolumn{4}{c}{ Gestational Age in Days } \\
\cline { 2 - 5 } & 38 & 46 & 56 & 61 \\
\hline $\begin{array}{l}\text { Number of fetuses } \\
\text { Averaged crown to }\end{array}$ & 3 & 2 & 2 & 3 \\
$\quad$ rump length (mm) & & 86 & 120 & 126 \\
$\begin{array}{c}\text { Range of eye weight } \\
\text { (mg) }\end{array}$ & $35-48$ & $125-145$ & $300-350$ & $340-420$ \\
$\begin{array}{l}\text { Volume of HRP }(\mu \mathrm{l}) \\
\left.\text { Amount of [ }{ }^{3} \mathrm{H}\right] \mathrm{leu}-\end{array}$ & 5 & 5 & 10 & 10 \\
$\quad$ cine $(\mu \mathrm{Ci})$ & 20 & 25 & 75 & 90 \\
\hline
\end{tabular}

penetrated by extending axons. As in the DLGn, the coarse collicular label was omnipresent, and this suggests that, at E38, the superior colliculus also was being overgrown by retinal fibers.

Heavy coarse grained label also filled the medial and lateral portions of the ipsilateral tectal mantle (Fig. 2, right side). As on the contralateral side, the central band was considerably less intensely labeled. Along the anteroposterior axis, the heavy label extended roughly $2.6 \mathrm{~mm}$ from the pretectal border to within a few hundred micrometers of the caudal tip of the superior colliculus. The peroxidase label in the most posterior $300 \mu \mathrm{m}$ was not heavy, but it was nevertheless distinct. The meager uncrossed projection to the extreme caudal pole of the E38(5) fetus may represent the precursor of the monocular cresent seen in mature cats (Graybiel, 1976).

Autoradiographic material at E38 did not match the quality of the peroxidase material. The label was only marginally above the background level at the dorsal margin of the ipsilateral tectal anlage, and although the contralateral label was moderately intense, it failed to resolve the finer details of the retinal projection evident in the peroxidase material.

$E 46$. The majority of E46 material was derived from one fetus $(E 46(2))$ in which both the peroxidase and autoradiographic methods were successful. The distribution of peroxidase label at this age is shown in Figure 4. The contralateral projection demonstrated by the peroxidase method was extremely dense and moderately coarse grained. In distinction to the younger fetuses, the label was distributed with greater uniformity along the mediolateral axis. Small clusters of the TMB chromogen occasionally were seen as deep as $400 \mu \mathrm{m}$ below the dorsal surface. Closer to the tectal margin, the density of chromogen at E46 was too high to distinguish individual clusters, but it is probable that, even at this age, the superior colliculus is the recipient of new axon ingrowth.

The contralateral autoradiographic label confirmed the picture obtained using the peroxidase method. Figure $5 A$, an autoradiograph through the anterior contralateral superior colliculus, demonstrates a significant change in the quality of label with depth. The dorsal $100 \mu \mathrm{m}$ of the collicular label is dense and uniform, whereas the ventral $150 \mu \mathrm{m}$ of label is mottled. The significance of this variation in the quality of autoradiographic and peroxidase label with depth is not known. It is possible that the mottled appearance in the deeper half of the plate is caused by $(i)$ heavily labeled fasciculi of retinal fibers, (ii) aggregates of growth cones, or (iii) the particular type of retinal axon arborizing or growing in the deeper portions of the retinorecipient laminae. In a study of the prenatal development of the retinofugal projections in the rat, Lund and Bunt (1976) found that the initial complement of retinal fibers coursed tangentially along the surface of the tectum. The majority of these fibers eventually came to lie under the stratum griseum superficiale (SGS) to form the stratum opticum. At E38, the heaviest label was located just below the pia, whereas by E46, some of the heaviest and most coarse label was located along the ventral margin of the tectal mantle. The mottled appearance of label in far rostral sections through the E46 midbrain thus may represent the formation of the stratum opticum.

Between E38 and E46, there was a significant change in the quality and distribution of ipsilateral label. The granularity of the TMB chromogen at E46, although still coarse compared to older fetal and neonatal material, was finer than that seen 8 days earlier, especially in the more rostral sections. The granularity of the label was most heavily textured along the ventromedial portion of the tectal plate in the region corresponding to the area of highest cell population density seen in Nissl-counterstained sections (Fig. $5 B$ ). The more superficial label was more homogeneous than that seen along the ventral margin of the tectal plate except in the far caudal colliculus where the sparse superficial label was particularly coarse. However, it should be pointed out that the tectal plate was thinner in more caudal sections so that a comparison based on depth may not be appropriate. The change in the grain of peroxidase label may be due to the elaboration of finer axonal arbors in the upper half of the mantle.

Two distinct tiers of ipsilateral peroxidase and autoradiographic label were evident in sections through the middle and caudal half of the superior colliculus as shown under dark-field illumination in Figure 6. At this gestational age, cellular lamination was not apparent in Nisslcounterstained sections, and thus it was not possible to relate these tiers of label to specific collicular layers. The upper, more dense and finer grained tier of label extended as far as $35 \mu \mathrm{m}$ below the pia mater, whereas the lower tier of more coarse label was heaviest close to the bottom of the tectal plate 80 to $140 \mu \mathrm{m}$ beneath the dorsal surface. It is possible that the lower tier of label is composed of stained axons of passage and growth cones and may presage the development of the stratum opticum, but if this were the case, it is difficult to understand why the bottom tier would be most evident in more caudal sections. An alternate possibility is that each of the two tiers receives a distinct class of retinal input, since it is known that, in the mature cat, neurons giving rise to the uncrossed projection form a heterogeneous population (Fukuda and Stone, 1974; Wässle and Illing, 1980).

Even as late as E46, uncrossed label covered the entire tectal plate. This expansive projection was seen in both peroxidase and autoradiographic material. At E46, there was no indication that the undecussated retinocollicular projection had begun to retract from either the anterior or posterior poles of the superior colliculus. The reorganization which occurs between E38 and E46 suggests either the onset of the elaboration of finer axonal plexuses 


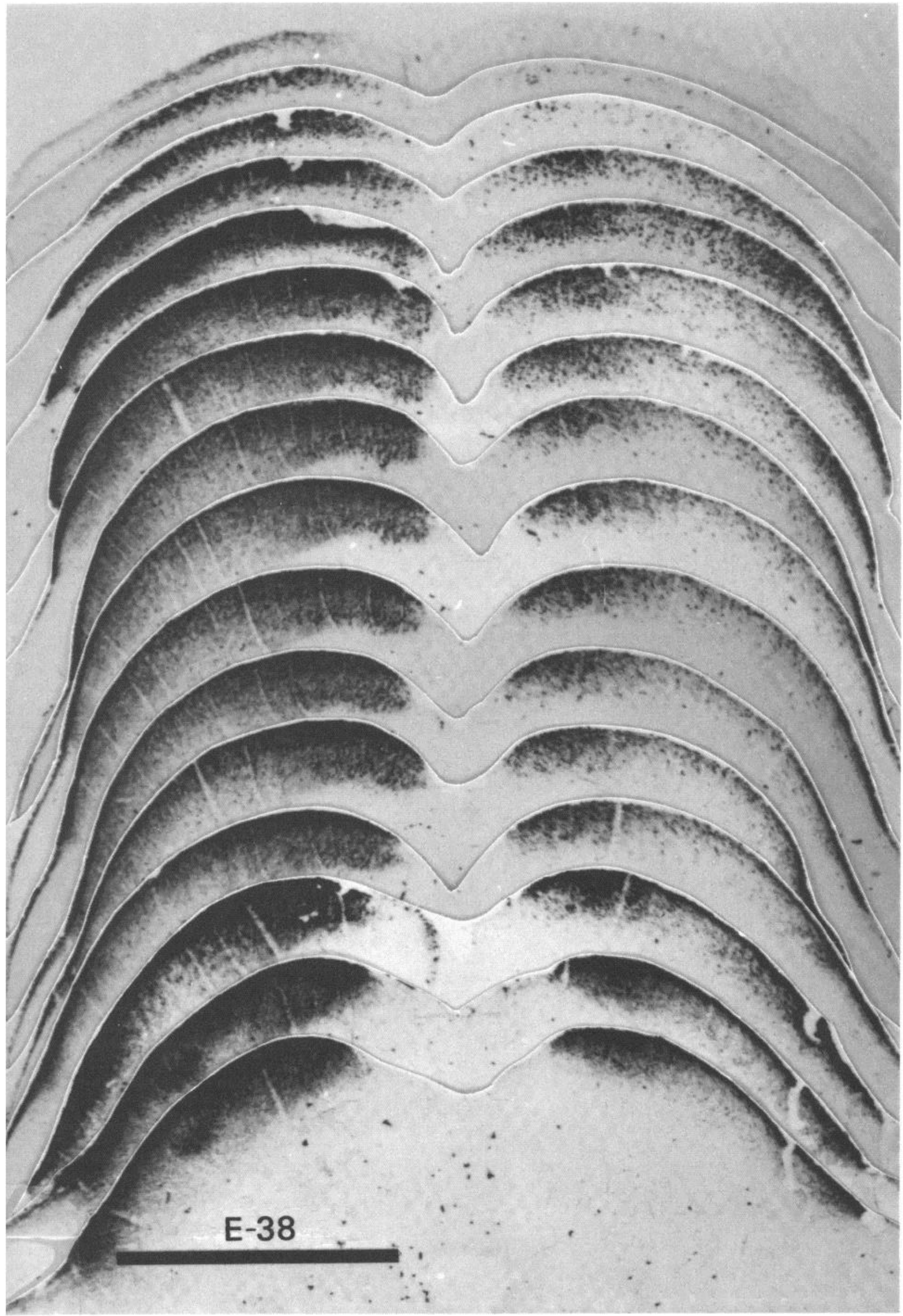

Figure 2. The retinal projection to the superior colliculus of fetus E38(5) demonstrated by the anterograde transport of HRP. The rostral pole of the superior colliculus is shown in the lowest photograph of the montage, and the caudal pole is shown in the uppermost photograph. The left side of the montage is contralateral to the eye which received the peroxidase injection. Note how extensive the uncrossed projection to the superior colliculus is at this gestational age, especially in comparison with that demonstrated in older fetuses (see Figs. 7 and 9). Adjacent sections are spaced approximately $150 \mu \mathrm{m}$ apart. Calibration bar, 1 $\mathrm{mm}$. 


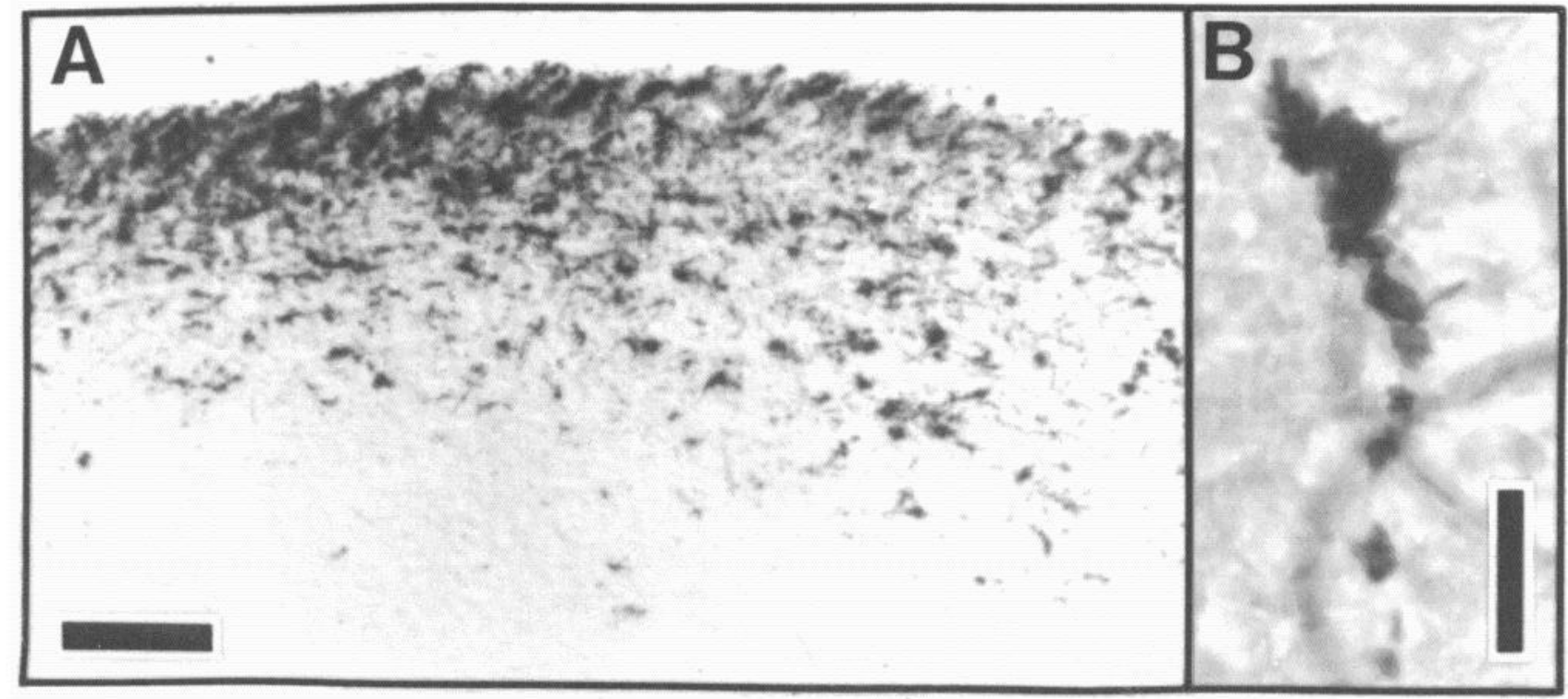

Figure 3. HRP-TMB label at E38. A, Coarse grained peroxidase label in the caudal ipsilateral superior colliculus of fetus E38(5). B, Peroxidase-labeled growth cone in the contralateral DLGn of the same fetus, E38(5). Calibration bar, $50 \mu \mathrm{m}$ in $A ; 5$ $\mu \mathrm{m}$ in $B$.

or the segregation of particular types of ganglion cell axons.

E56. Between E46 and E56, there was only one notable change in the overall distribution of peroxidase and autoradiographic label in the contralateral superior colliculus. At E56, the central portion of the anterior third of the contralateral colliculus was only sparsely labeled. This region of light labeling is seen most clearly in Figure 7. At this gestational age, the incipient strata of the superior colliculus could be distinguished in Nisslcounterstained sections, and it appeared that the erosion of label was restricted to the upper middle portion of the SGS. The set of autoradiographs through the anterior third of the superior colliculus from this fetus (E56(2)) also demonstrated less intense label. In the mature cat, monkey, and ape (Graybiel, 1975; Hubel et al., 1975; Tigges et al., 1977; Pollack and Hickey, 1979), the fovea centralis representation on the superior colliculus has been shown by anterograde transport methods to receive a relatively sparse retinal input. Thus, we presume that the lightly labeled zone seen at E56 represents the central portion of the retina.

In spite of careful examination and reconstruction of the contralateral collicular label, no sign of the "representation" of the contralateral optic disc, seen in the adult cat as an unlabeled patch (Graybiel, 1975), could be found. Since every section was saved and reacted in fetus E56(2) and every other section in fetus E56(1), it is improbable that we simply neglected to find such a gap. The exclusion of contralateral label from the area corresponding to the optic disc had not progressed noticeably at this gestational age.

The most pronounced change between E46 and E56 was apparent in the pattern of ipsilateral label. As shown in Figure 7, and in greater detail in Figure 8, the caudal ipsilateral superior colliculus was devoid of peroxidase label in fetus E56(2). This region was also devoid of autoradiographic label. In addition, the most rostral segment was only very sparsely labeled. The quality of the ipsilateral peroxidase label at E56 differed from that seen in younger fetal material. The label was not distributed uniformly within the superior colliculus, but it was nevertheless of an even and fine texture. A distinction similar to that made at E46 between fine superficial and coarse deep label was not possible. The most superficial label, restricted to the upper margin of the SGS, was very intense (Figs. 7 and 8 ). The more ventral label was diffuse and could not be assigned to any particular sublamina of the SGS. A diffuse band of label, running rostrocaudally along the crown of the ipsilateral superior colliculus, is clearly shown in Figure 8 . The focus of this label is over the intermediate lamina of the SGS. Graybiel (1976) has made high resolution reconstructions of the ipsilateral retinocollicular projection in mature cats and she describes numerous bands or columns of label oriented along the anteroposterior axis. It is probable that this banding is incipient at E56.

E61. A few days before birth, the crossed retinal projection to the superior colliculus appeared similar to that of the mature cat. E61 was the earliest age at which the stratum zonale was devoid of retinally derived label (Figs. 9 and 12). In the mature cat, the stratum zonale consists largely of astrocytic processes, intrinsic and cortical axons, and small neurons (Langer, 1975). It contains few, if any, retinal terminals at E61, in the neonate (R. R. Mize and P. Sterling, research in progress), or the adult (Sterling, 1973).

Another feature which distinguished the E61 fetal projection from that of younger fetuses was the unequivocal presence of two tiers of retinal label in the anterior onehalf of the contralateral superior colliculus (Fig. 9). The upper tier was composed of a virtually unbroken sheet of very dense label 60 to $80 \mu \mathrm{m}$ thick. This dense sheet of label directly abutted the stratum zonale but was clearly restricted to the superficial portion of the SGS (SGS-1 of Kanaseki and Sprague, 1974). This tectal layer is the major recipient of retinal input in the mature cat (Sterling, 1973; Mize, 1981). Of interest in this regard is the 


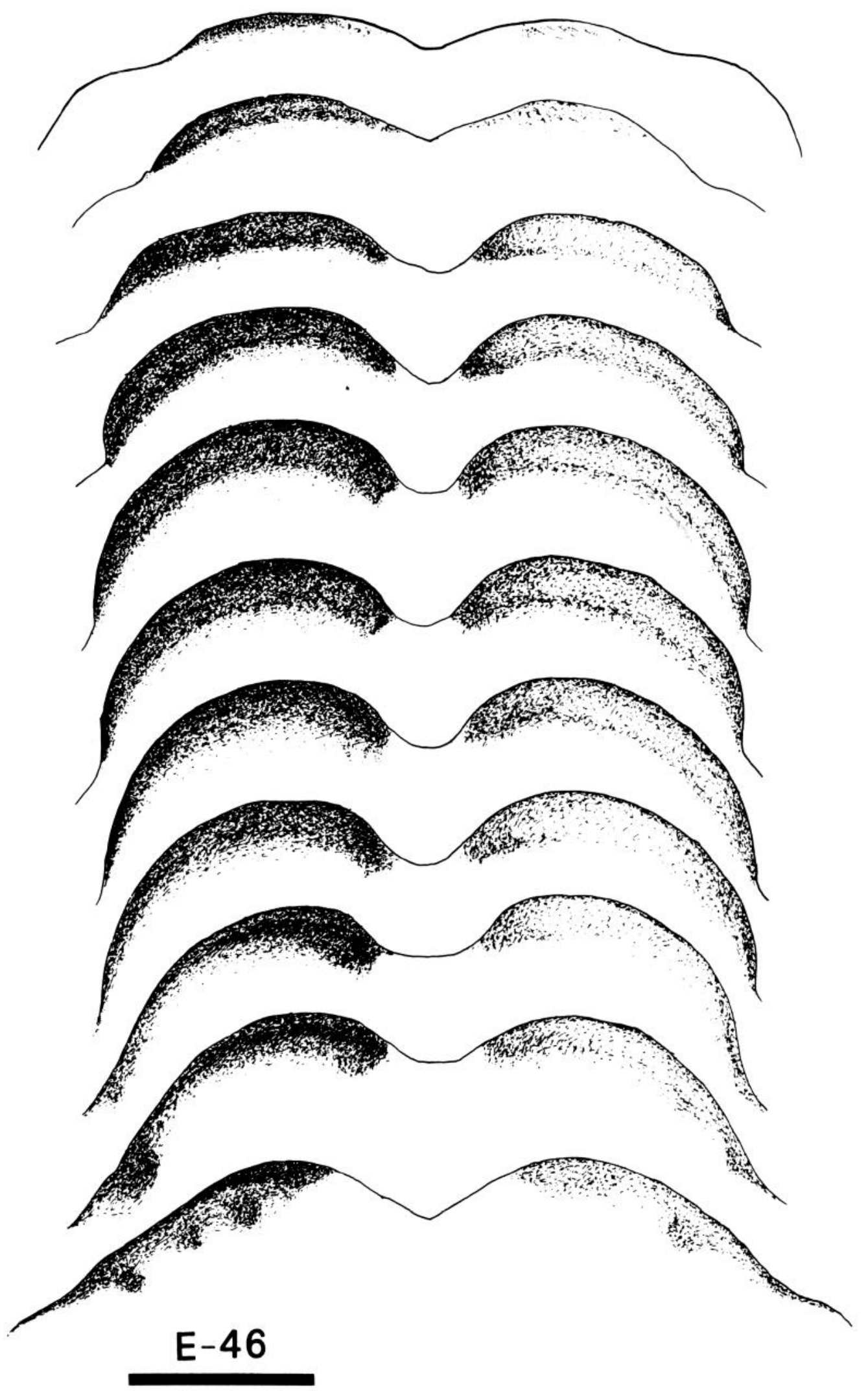

Figure 4. The distribution of label within the superior colliculus of fetus E46(2). This series of drawings was made using a Bausch and Lomb projection microscope. Conventions are as in Figure 2. Two tiers of label are evident on the ipsilateral (right) side. Adjacent sections are spaced approximately $200 \mu \mathrm{m}$ apart. Calibration bar, $1 \mathrm{~mm}$. 

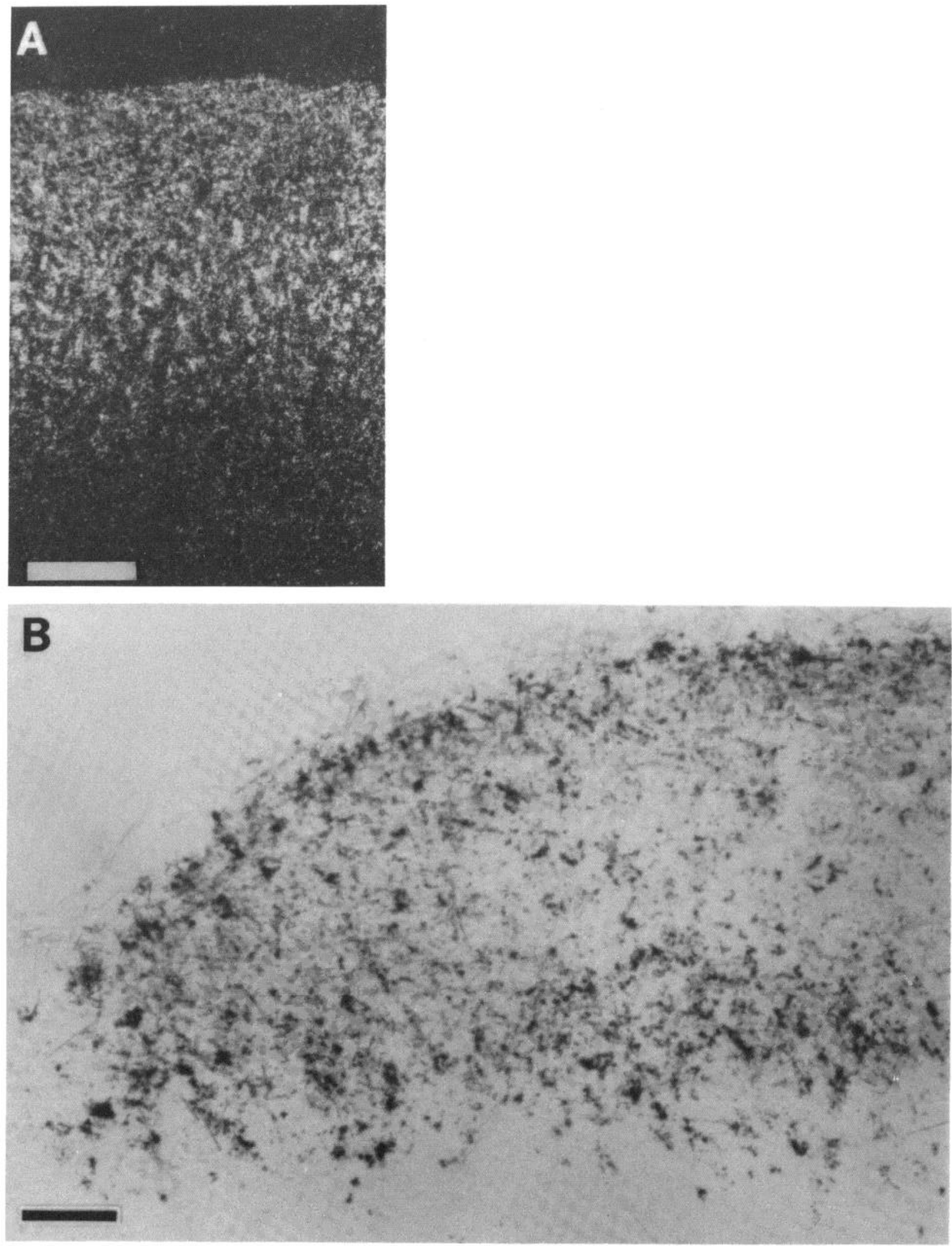

Figure 5. A, Autoradiograph showing the pattern of label in the rostral contralateral superior colliculus of fetus E46(2). This dark-field-illuminated micrograph shows the change in the quality of label with depth: the superficial label is relatively homogeneous; the deeper label is mottled. The deeper label may presage the formation of the stratum opticum (see text for additional comments). $B$, Granularity of peroxidase label along the medial edge of the ipsilateral superior colliculus of fetus $\mathrm{E} 46(2)$. This coronal section is from the caudal one-third of the superior colliculus. Medial is to the left. Calibration bars, $50 \mu \mathrm{m}$. 


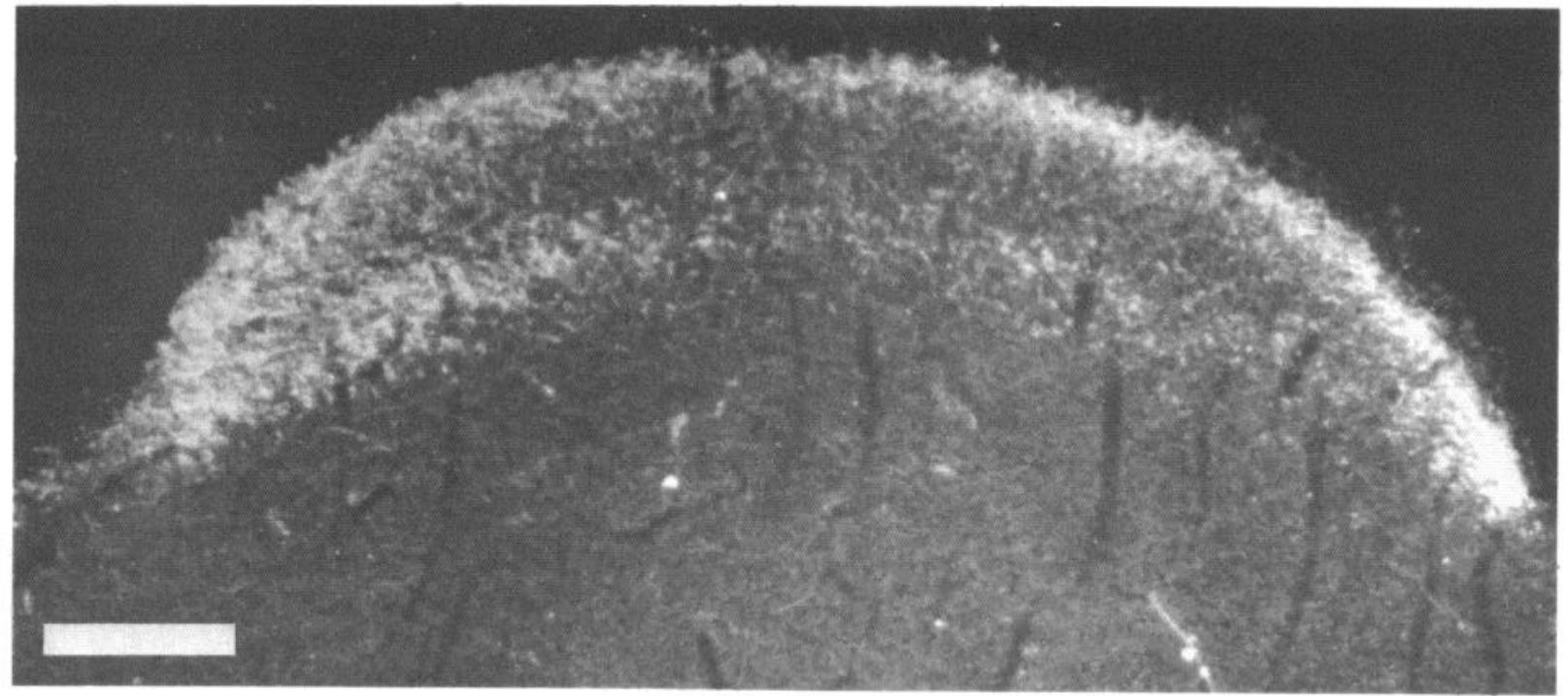

Figure 6. Two relatively distinct tiers of HRP-TMB label are evident in this coronal section through the ipsilateral superior colliculus of fetus E46(2). As in Figure 4, the label is lighter than background. This coronal section was taken $1.9 \mathrm{~mm}$ from the rostral collicular border. Medial is to the left. Calibration bar, $200 \mu \mathrm{m}$.

recent observation that focal peroxidase injections made into the upper SGS result in the retrograde labeling of small ganglion cells of the $\gamma$ class (Itoh et al., 1980). The deep tier of retinal label was 100 to $150 \mu \mathrm{m}$ thick and extended down to the stratum opticum. This tier was largely restricted to the deep lamina of the superficial gray, SGS-3. The more sparsely labeled stratum sandwiched between these tiers corresponded to SGS-2, which at $\mathrm{E} 61$ received the bulk of the uncrossed retinal input. The contralateral projection to SGS-2 took the form of poorly defined bands of label extending from SGS-1 to SGS-3, with center-to-center separations ranging from 150 to $250 \mu \mathrm{m}$. Defining the borders of diffuse bands precisely was difficult in both autoradiographic and peroxidase material, but their breadth ranged from 60 to $150 \mu \mathrm{m}$.

The regions of particularly sparse label in SGS-2 which lay between bands presumably received a heavy ipsilateral retinal input. Since alternate sections were processed to demonstrate the uncrossed peroxidase or the crossed autoradiographic label, the location of ipsilateral patches or bands could be related directly to the distribution of contralateral label (Fig. 10). Discrete patches of ipsilaterally derived label were evident along the mediolateral axis and appeared to be centered within SGS-2. Clearly, the notion that crossed and uncrossed terminal arbors are at least partially segregated is borne out by the double anterograde labeling technique as has been suggested previously by Graybiel (1975) and Harting and Guillery (1976). Graybiel and Nauta also have depicted the pattern of ipsilateral banding in the cat several days before birth (results cited in Graybiel, 1975).

In the adult cat, the segregation of retinal fibers is most pronounced at the "representation" of the optic disc. In only one of three E61 fetuses could we demonstrate the gap of label at the contralateral "representation" of the optic disc (Fig. 11A). This small gap in the peroxidase label was restricted to SGS-1 and the upper part of SGS-2. In an adjacent autoradiographic section, a patch of ipsilaterally derived label was found which corresponded to, and presumably filled, the incipient optic disc gap. However, not until the day of birth was the contralateral "representation" of the optic disc clear of label. The gap extended through the full depth of the superficial gray (Fig. 11B).

As may be seen in Figure 12, in the rostral half of the ipsilateral superior colliculus at E61, the discrete banded projection was overlain by a superficial tier of dense label apposed to the ventral margin of the stratum zonale. This sheet of superficial label actually was composed of a set of numerous thin plates of label. Farther posterior, the deep tier of banded or patchy label merged dorsally with the superficial tier. The superficial label shifts gradually toward the extreme lateral margin of the SGS before vanishing completely.

The ipsilateral retinal projection described by Graybiel (1976) and shown in her Figures $1 b$ and $2, a$ and $b$, resembles that seen in fetus E61(4). She also noted the presence of a fractured superficial sheet of label in addition to the more ventral bands in SGS-2. Thus, a few days before birth, the retinal projection to the superior colliculus appears similar to that described by Graybiel $(1975,1976)$ and Harting and Guillery (1976) for the adult cat. In particular, at E61, as in the adult cat, the retinocollicular projection has the following attributes: $(i)$ clear patches of label are seen in the ipsilateral colliculus which, in some instances, correspond to gaps in label derived from the contralateral retina; (ii) the stratum zonale is devoid of label; and (iii) the rostral and caudal margins of the ipsilateral superior colliculus are unlabeled. It is of course possible that the pattern of the retinocollicular projection undergoes further changes; however, any modifications in the distribution of retinotectal fibers after birth are certainly less dramatic than those which occur during the latter half of gestation.

\section{Discussion}

This study describes the formation of retinal projections to the superior colliculus of the cat. We have found that, by the 38th day of gestation, each retina projects 


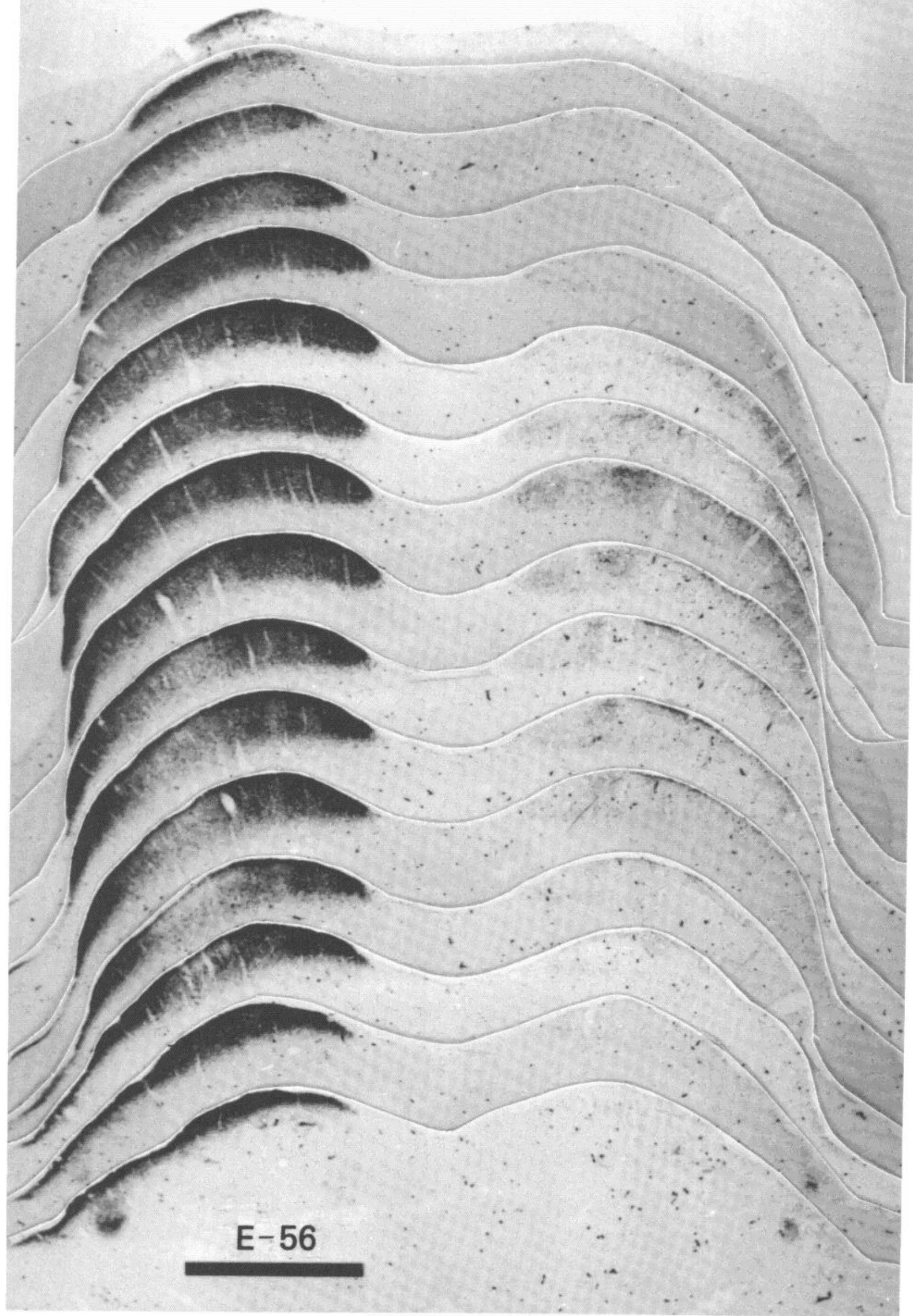

Figure 7. A photomontage of 16 sections spaced approximately $180 \mu \mathrm{m}$ apart showing peroxidase label in the contralateral (left) and ipsilateral (right) superior colliculus of fetus E56(2). Conventions are as in Figure 2. Note the substantial change in the distribution of ipsilateral label in comparison to E38(5) (Fig. 2). The ipsilateral label is restricted to the central region, but in distinction to the E61 material (Figs. 9 and 10), the label is still diffuse. The vertical gaps in label seen especially on the contralateral side are vascular channels. Calibration bar, $1 \mathrm{~mm}$. 


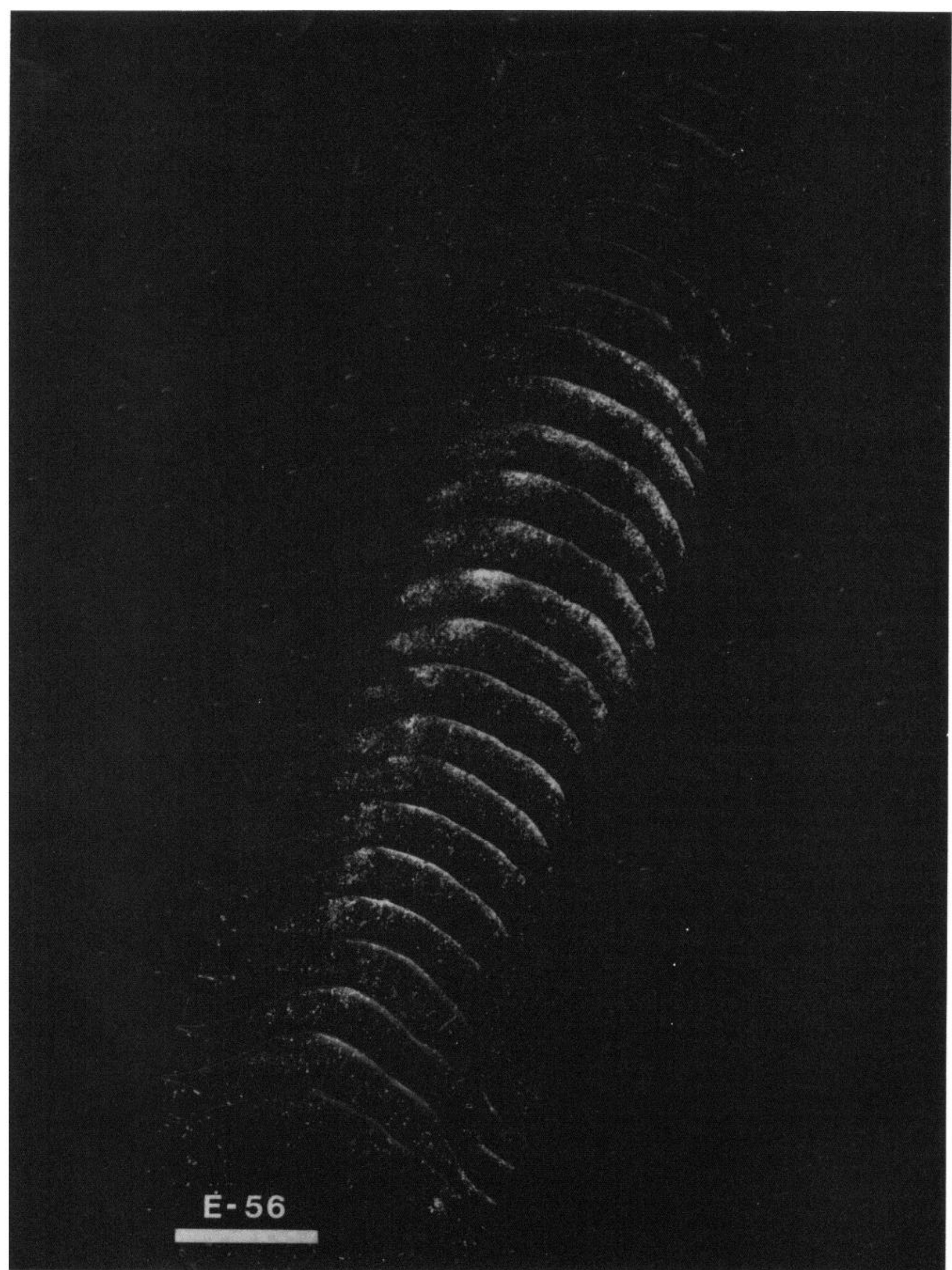

Figure 8. Montage of the ipsilateral superior colliculus of fetus E56(2). The dark-field effect was obtained using two Polaroid type HN32 linear polarizers crossed for maximum extinction. Adjacent sections are spaced approximately $120 \mu \mathrm{m}$ apart. Banding of the ipsilateral retinocollicular projection may be incipient at this gestational age. Conventions are as in Figure 2. Calibration bar, $1 \mathrm{~mm}$. 


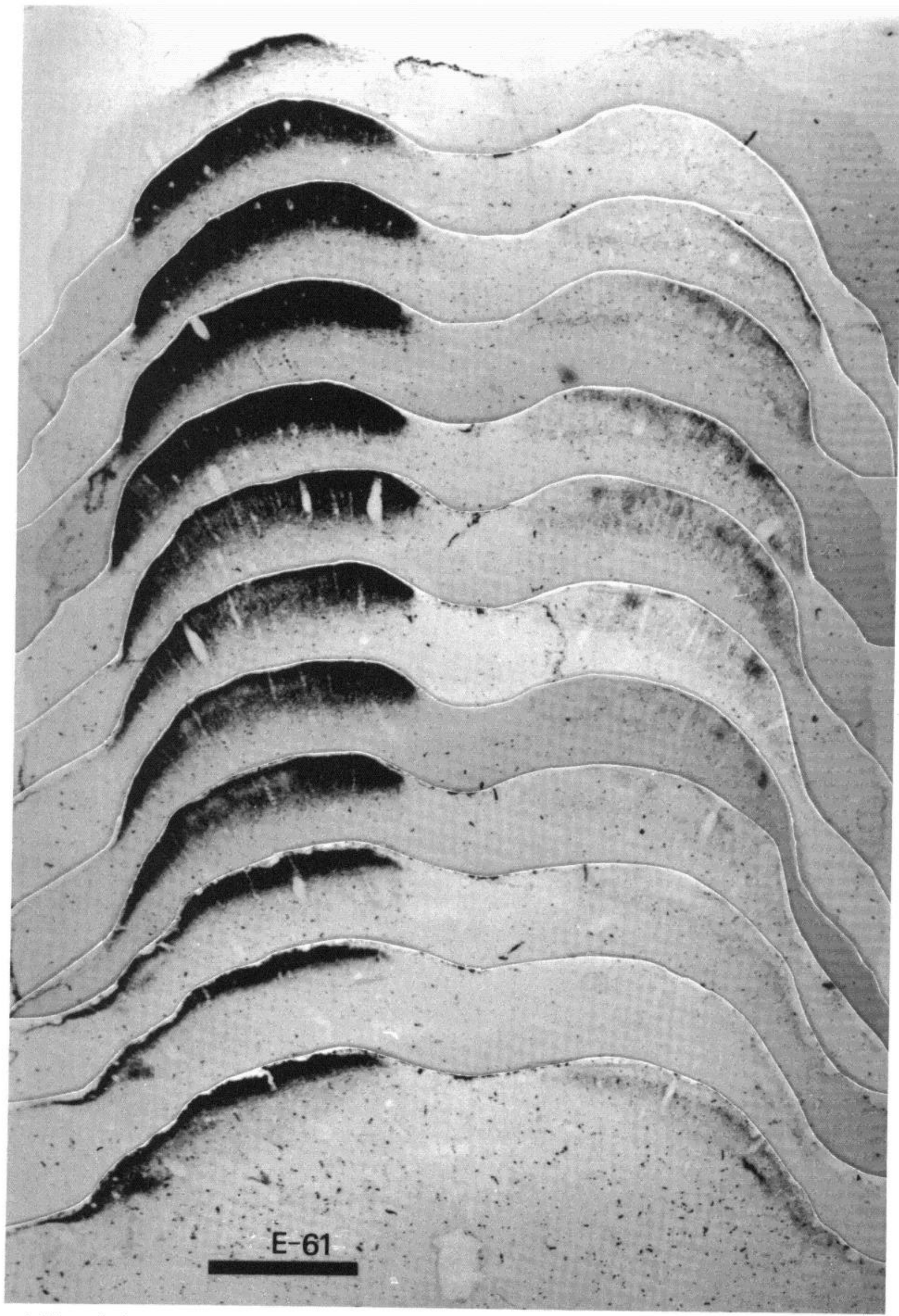

Figure 9. The retinal projection to the superior colliculus of fetus E61(4) demonstrated by the orthograde transport of HRP. Conventions are as in Figures 2 and 7. On the contralateral (left) side, areas of less intense label are found within the middle of the stratum griseum superficiale. Adjacent sections are spaced approximately $240 \mu \mathrm{m}$ apart except between the upper two photographs of the montage between which the spacing is approximately $500 \mu \mathrm{m}$. Calibration bar, $1 \mathrm{~mm}$. 


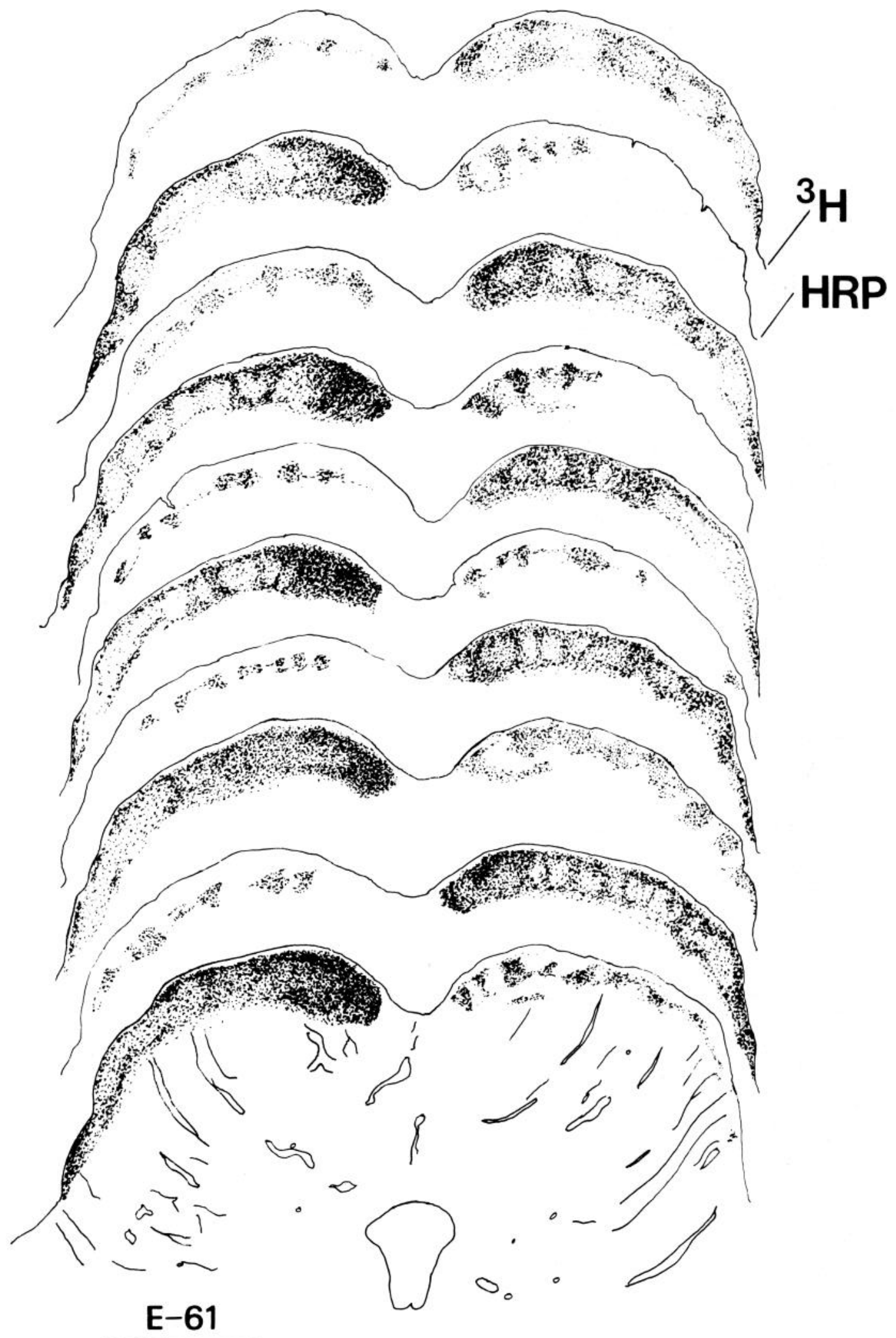

Figure 10. The partial segregation of crossed and uncrossed retinal fibers to the superior colliculus of fetus E61(5). Alternate sections treated for autoradiography $\left({ }^{3} \mathrm{H}\right)$ or for the presence of peroxidase $(H R P)$ were drawn under dark-field illumination. Peroxidase sections show the crossed retinal projection to the left, whereas the autoradiographic sections show the uncrossed projection to the left. Upper drawings are at more caudal levels of the superior colliculus. Calibration bar, $1 \mathrm{~mm}$. 

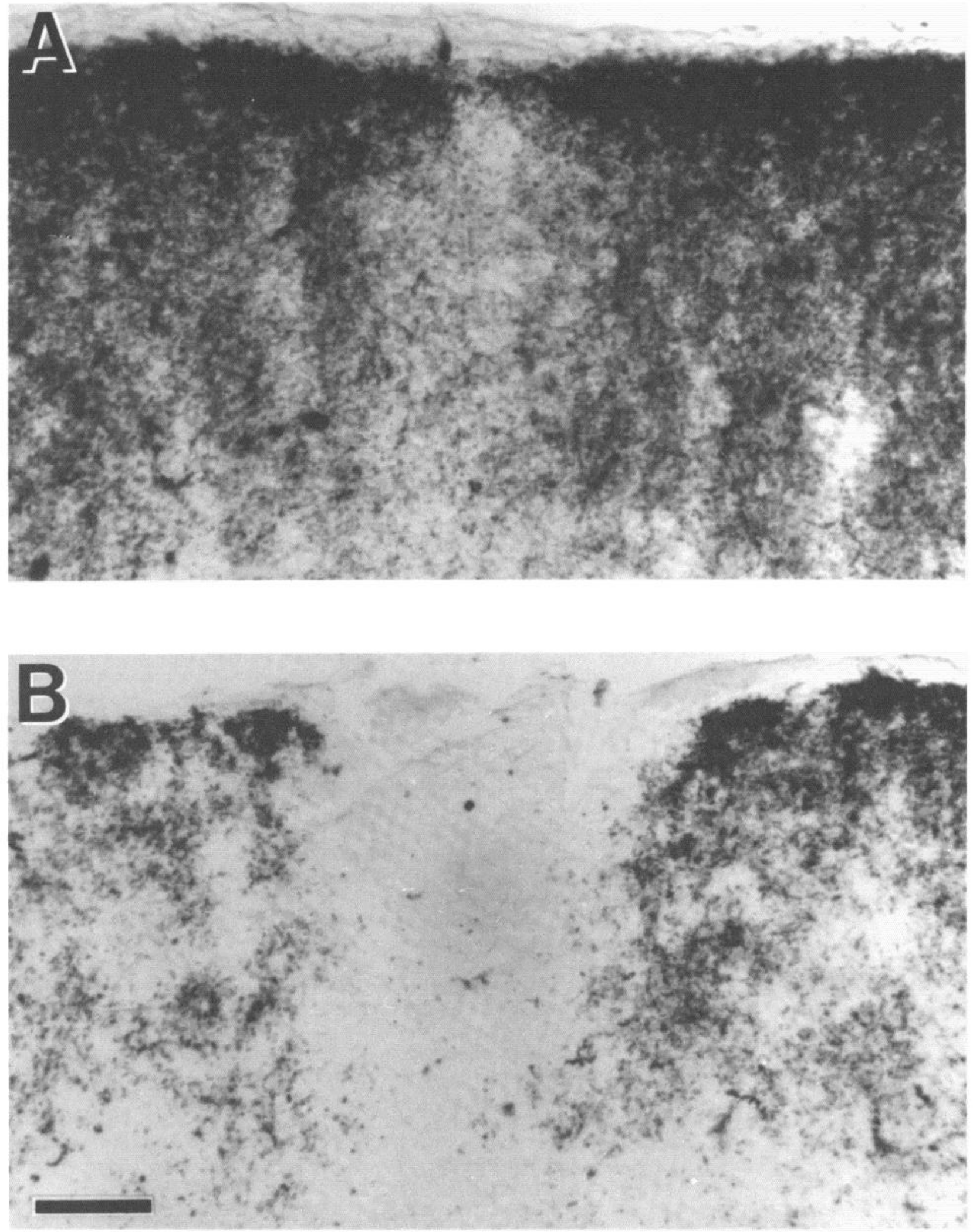

Figure 11. The optic disc "representation" gap seen in HRP-TMB-reacted tissue. A, Partial clearing of the label is evident in the stratum zonale and the upper portion of stratum griseum superficiale of fetus E61(3). $B$, In the neonate, P0(1), the gap extends through the stratum zonale and the entire stratum griseum superficiale. Calibration bar, $50 \mu \mathrm{m}$ for $A$ and $B$.

bilaterally over the entire tectal plate. The amount of label in the posterior third of the ipsilateral superior colliculus diminishes between E46 and E56 such that, by E56, the uncrossed retinal projection, as in the mature cat, is restricted to a broad central band of the superior colliculus. During the last 10 days of term, there appears to be no further reduction in the volume of ipsilaterally derived label, and the previously overlapping projections 


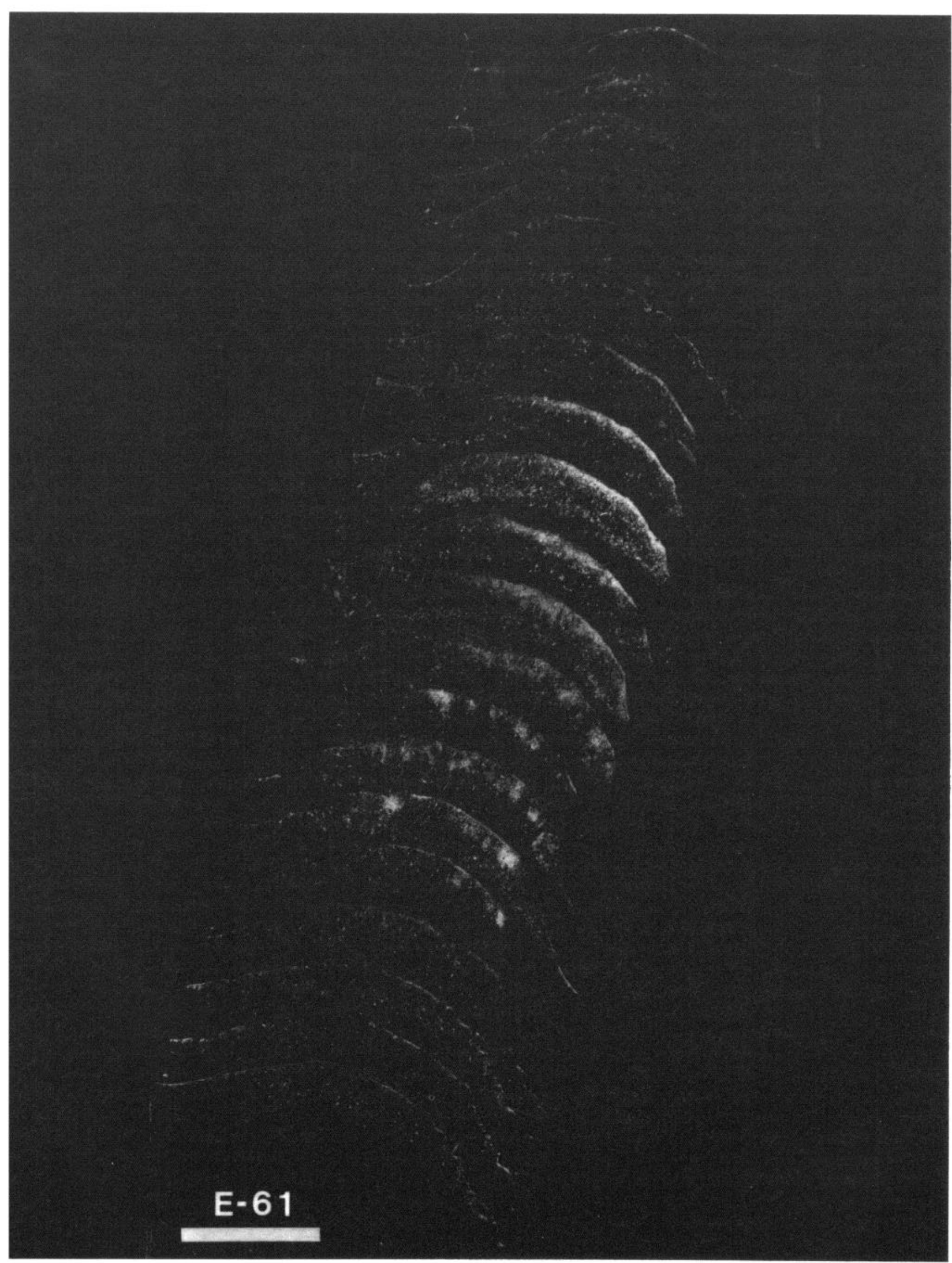

Figure 12. Polarized light photomontage of the uncrossed retinal projection to fetus E61(4). Adjacent sections are spaced approximately $160 \mu \mathrm{m}$ apart. Patches or bands of label are now clearly evident within the stratum griseum superficiale. Conventions are as in Figure 2. Calibration bar, $1 \mathrm{~mm}$. 
from the eyes become partially segregated. Several days before birth, the retinal projection to the superior colliculus has a pattern similar to that demonstrated in the mature cat. The retinal innervation of the ipsilateral superior colliculus appears to involve at least three steps: (i) a generous axonal outgrowth covering the complete tectal sheet, (ii) a retraction along the anteroposterior axis such that the projection is excluded from both the rostral and caudal collicular poles, and (iii) a condensation of the uncrossed terminal arbors into bands restricted largely to SGS-2.

A number of difficulties could mar the interpretation of the results. These problems are common to studies employing the orthograde transport of tracer substances but may be of greater significance in this developmental study. The uptake of tracer compounds from the vitreous could be influenced by at least the following variables: uniformity of tracer distribution in the vitreous, effective vitreal concentration of the tracer, and uptake competence of the retinal ganglion cells as a function of age, cell class, and retinal position. The first of these variables, intravitreal distribution and concentration of tracer, obviously could affect the pattern of terminal label. If it is assumed that all portions of the developing retina project to the contralateral superior colliculus, then the pattern of label on the contralateral side provides an indication of the uniformity of tracer distribution within the eye. Since, at all ages, heavy label was distributed throughout the full rostrocaudal extent of the contralateral superior colliculus and since both eyes received injections of tracer substances which yielded complementary patterns of label (see Fig. 10), it is unlikely that the absence of label seen in rostral and caudal regions of the ipsilateral superior colliculus at progressively older ages is simply due to such a methodological artifact.

The second factor, uptake and transport as a function of cell birth date (gestational age at time of final mitosis), remains obscure. Data on the time of the last mitosis of matrix cells destined to differentiate as retinal ganglion cells are not yet available for any species of carnivore. The results of Sidman (1961) and LaVail and Rakic. (research in progress, cited in Rakic, 1977a) suggest a rough central-to-peripheral gradient in the time of generation of neurons destined to occupy the ganglion cell layer of the mammalian retina. Since we have shown that peroxidase label in the superior colliculus at E38 and E46 extends from the rostral to the caudal poles, it could be argued that, even as early as E38, axons originating from peripheral temporal ganglion cells have extended into the most caudal portion of the superior colliculus. This argument is weakened by the underlying assumption that fetal topography is similar to that of the adult. An alternate possibility is that early arriving axons originating from the central retina overgrow the entire tectal mantle and only later become compressed into their adult terminal field. The retrograde labeling of ganglion cells from the fetal superior colliculus could resolve this problem.

Retinal ganglion cells have been categorized using morphological and physiological criteria into at least three classes (Boycott and Wässle, 1974; Stone and Fukuda, 1974; Cleland and Levick, 1974a, b). There is no indication in the mature cat that these classes can be distinguished by the avidity with which they incorporate or transport substances along their axons. We (unpublished observations) have found that structures which, in the mature cat, receive predominantly X-and/or Y-type retinal input (i.e., the main laminae of the DLGn and the medial interlaminar nucleus (Dreher and Sefton, 1979)) appear to be labeled as well at E38 as those structures receiving predominantly $\mathrm{W}$-type input (i.e., the ventral lateral geniculate nucleus (Spear et al., 1977) and the superior colliculus (Hoffmann, 1973)). It is, therefore, doubtful that the developmental sequence demonstrated in this paper is secondary to altered patterns of uptake and transport by the three main classes of ganglion cells.

Finally, the retinal locus of the ganglion cell soma could influence the rate of tracer uptake. Neurons within portions of the retina with a relatively dispersed cell population may accumulate greater quantities of tracer due to low mobility of the tracer either in the vitreous humor or within the interstices of the optic fiber and ganglion cell layers. Stone et al. (1981) have shown that the distribution of young neurons within the incipient ganglion cell layer is remarkably uniform at E47. However, by E57, they found an 18:1 central-to-peripheral ganglion cell population density gradient, and therefore the possibility of impaired orthograde transport from the central retina cannot be discounted. In the adult primate, for example, the central retinal projection to the superior colliculus is not seen clearly using orthograde transport of tritiated compounds (Hubel et al., 1975; Tigges et al., 1977) or degeneration methods (Wilson and Toyne, 1970). Since ganglion cell somas are smaller and more densely packed around the foveal pit, with the ganglion cell layer being up to six cells deep (Hendrickson and Kupfer, 1976), the availability of tracer per cell may be considerably less at central than at peripheral retinal loci. The recent demonstration by Cowey and Perry (1980) of parafoveal efferents projecting to the anterior portion of the macaque monkey superior colliculus after HRP backfills emphasizes the value of this technique in confirming and extending the results obtained with orthograde methods.

The gestation period of the cat averages 65 days. Although the time of origin of young neurons in the cat visual system has not been well documented as has been done for the mouse by Sidman (1961) and for the macaque monkey by Rakic $(1974,1976,1977 b)$, the report of Hickey and Cox (1979) has shown that the majority of neurons contributing to the DLGn are postmitotic at midgestation. Since, in both the monkey (Rakic, 1977b) and the rodent (Brückner et al., 1976), the period of DLGn neurogenesis overlaps that of the superior colliculus, it is probable that, by E38, the earliest age examined in this study, the majority of collicular neurons have been generated. Whether the full complement of cells has migrated into the tectal plate by E38 is unknown. We have observed very dense packing of cells along the medial margin of the tectal plate at E38 and particularly E46, and this may be related to the migrational course of the neuro- or glioblasts.

The partial retraction during development of an ipsilateral retinocollicular projection has been described in the rhesus monkey (Rakic, 1977a), the rat (Land and Lund, 1979), the hamster (Frost et al., 1979), and the 
opossum (Cavalcante and Rocha-Miranda, 1978). The withdrawal of an uncrossed projection may be a general feature of mammalian, if not vertebrate, ontogeny. Northcutt and his colleagues have raised the possibility that bilateral retinofugal projections were present in ancestral vertebrates, partly on the basis of the distinct ipsilateral projections in an agnathan, the lamprey (Northcutt and Przybylski, 1973), in a holostean, the garfish (Northcutt and Butler, 1976), an elasmobranch (Northcutt and Wathey, 1980), and in the primitive Australian lungfish (Northcutt, 1980). It would be worthwhile to employ the anterograde transport of peroxidase enzyme in a developmental study of teleostean and anuran retinofugal projections to see if short lived ipsilateral retinal projections could be demonstrated.

The progressive restriction and subsequent segregation of label within the developing tectal plate of the fetal cat could be accounted for by at least three phenomena. First, it is conceivable that axoplasmic transport rates of retinal ganglion cells could vary during prenatal development. In the extreme case, select groups of fibers which readily transport tracers early in development may no longer do so at later gestational ages. At present, this unsettling possibility cannot be ruled out. Although axoplasmic transport methods, and in particular the anterograde transport of horseradish peroxidase, have been shown to be highly sensitive for demonstrating developing retinofugal projections (So and Schneider, 1978; Land and Lund, 1979), it may nonetheless be worthwhile to employ degeneration methods, especially in conjunction with electron microscopy, to examine this problem.

Second, the redistribution of retinocollicular label may reflect structural alterations in axonal arbors. This could involve a local and selective regression of portions of axon arbors. Mason (1980), for instance, has shown considerable remodeling of terminal segments in the kitten's lateral geniculate nucleus as late as 2 weeks after birth. Furthermore, the formation of ocular dominance slabs in the striate cortex of the cat has been associated with resorption of geniculostriate axon arbors (Hubel et al., 1977; LeVay and Stryker, 1979). The erosion of label also could result from the elimination of major axon collaterals. Such a mechanism has been shown to play a role in the reduction of the number of cortical neurons with interhemispheric connections (Innocenti, 1981; Ivy and Killackey, 1981). In the mature cat, some ganglion cell axons bifurcate to innervate the lateral geniculate and the superior colliculus (O'Leary, 1940; Bowling and Michael, 1980; Giolli, 1980). It is possible that the incidence of collateralization within the tract, and perhaps even at the chiasm (cf., Ramón y Cajal, 1911), is considerably higher during early stages of development. This suggestion is testable with retrograde double labeling methods (e.g., Kuypers et al., 1977; Illing, 1980; Jeffery et al., 1981).

Third, the changes in the labeling pattern may result from the degeneration of ganglion cells whose axons project to the colliculus during early development. There is now compelling evidence in the chicken (Rager and Rager, 1976; Hughes and McLoon, 1979; McLoon and Lund, 1980), rat (Kuwabara and Weidman, 1974; Land and Lund, 1979; Cunningham et al., 1981; Jeffery and Perry, 1981), and hamster (Frost et al., 1979; Sengelaub and Finlay, 1981) that retinal ganglion cell death is involved in the restructuring of the developing retinotectal pathway. In the cat, there is circumstantial evidence that this mechanism also plays a role in the early development of retinofugal connections. Thus, Stone et al. (1981) have estimated that, at E47, there are 4 to 8 times as many cells within the ganglion cell layer as in the adult (Stone, 1978). The sharp reduction in label within the ipsilateral superior colliculus between E46 and E56 appears to coincide with the precipitous drop in the number of neuronal profiles in the cat's ganglion cell layer.

The extent to which the phenomena discussed above contribute to the transformation in the pattern of retinocollicular label described in this paper is unknown. Intuitively, it seems reasonable that a combination of factors is involved in the formation of the mature retinotectal system. If this is the case, it will require considerable effort to assess the relative importance of each of these mechanisms at different stages of development.

\section{References}

Anker, R. L. (1977) The prenatal development of some of the visual pathways in the cat. J. Comp. Neurol. 173: 185-204.

Behan, M. (1981) Identification and distribution of retinocollicular terminals in the cat: An electron microscopic autoradiographic analysis. J. Comp. Neurol. 199: 1-15.

Bowling, D. B., and C. R. Michael (1980) Projection patterns of single physiologically characterized optic tract fibers in cat. Nature 286: 899-902.

Boycott, B. B., and H. Wässle (1974) The morphological types of ganglion cells of the domestic cat's retina. J. Physiol. (Lond.) 240: 397-419.

Brückner, G., V. Mareš, and D. Biesold (1976) Neurogenesis in the visual system of the rat. An autoradiographic investigation. J. Comp. Neurol. 166: 245-256.

Cavalcante, L. A., and C. E. Rocha-Miranda (1978) Postnatal development of retinogeniculate, retinopretectal and retinotectal projections in the opossum. Brain Res. 146: 231-248.

Cleland, B. G., and W. R. Levick (1974a) Brisk and sluggish concentrically organized ganglion cells in the cat's retina. J. Physiol. (Lond.) 240: 421-456.

Cleland, B. G., and W. R. Levick (1974b) Properties of rarely encountered types of ganglion cells in the cat's retina and an overall classification. J. Physiol. (Lond.) 240: 457-492.

Cowey, A., and V. H. Perry (1980) The projection of the fovea to the superior colliculus in rhesus monkeys. Neuroscience 5 : $53-61$.

Cragg, B. G. (1975) The development of synapses in the visual system of the cat. J. Comp. Neurol. 160: 147-166.

Cunningham, T. J., I. M. Mohler, and D. L. Giordano (1981) Naturally occurring neuron death in the ganglion cell layer of the neonatal rat: Morphology and evidence for regional correspondence with neuron death in the superior colliculus. Dev. Brain Res. 2: 203-215.

Currie, J., and W. M. Cowan (1975) The development of the retino-tectal projection in Rana pipiens. Dev. Biol. 46: 103-119.

Dreher, B., and A. J. Sefton (1979) Properties of neurons in cat's dorsal lateral geniculate nucleus: A comparison between medial interlaminar and laminated parts of the nucleus. $J$. Comp. Neurol. 183: 47-64.

Frost, D. O., K -F. So, and G. E. Schneider (1979) Postnatal development of retinal projections in Syrian hamster: A study using autoradiographic and anterograde degeneration techniques. Neuroscience 4: 1649-1677.

Fukuda, Y., and J. Stone (1974) Retinal distribution and central 
projections of $\mathrm{Y}-, \mathrm{X}-$, and $\mathrm{W}$-cells of the cat's retina. J. Neurophysiol. 37: 749-772.

Giolli, R. (1980) A review of axon collateralization in the mammalian visual system. Brain Behav. Evol. 17: 364-398.

Graybiel, A. M. (1975) Anatomical organization of retinotectal afferents in the cat: An autoradiographic study. Brain Res. 96: 1-23.

Graybiel, A. M. (1976) Evidence for banding of the cat's ipsilateral retinotectal connection. Brain Res. 114: 318-327.

Harting, J. K., and R. W. Guillery (1976) Organization of retinocollicular pathways in the cat. J. Comp. Neurol. 166: 133-144.

Hendrickson, A., and S. B. Edwards (1978) The use of axonal transport for autoradiographic tracing of pathways in the central nervous system. In Neuroanatomical Research Techniques, R. T. Roberston, ed., pp. 242-285, Academic Press, New York.

Hendrickson, A., and C. Kupfer (1976) The histogenesis of the fovea in the macaque monkey. Invest. Ophthalmol. 15: 746-756.

Hickey, T. L., and N. R. Cox (1979) Cell birth in the dorsal lateral geniculate nucleus of the cat: $\mathrm{A}{ }^{3} \mathrm{H}$-thymidine study. Soc. Neurosci. Abstr. 3: 788.

Hoffmann, K. -P. (1973) Conduction velocity in pathways from retina to superior colliculus in the cat: A correlation with receptive-field properties. J. Neurophysiol. 36: 409-424.

Hubel, D. H., S. LeVay, and T. N. Wiesel (1975) Mode of termination of retinotectal fibers in macaque monkey: An autoradiographic study. Brain Res. 96: 25-40.

Hubel, D. H., T. N. Wiesel, and S. LeVay (1977) Plasticity of ocular dominance columns in monkey striate cortex. Philos. Trans. R. Soc. Lond. (Biol.) 278: 377-409.

Hughes, W. F., and S. C. McLoon (1979) Ganglion cell death during normal retinal development in the chick: Comparisons with cell death induced by early target field destruction. Exp. Neurol. 66: 587-601.

Illing, R. -B. (1980) Axonal bifurcation of the cat retinal ganglion cells as demonstrated by retrograde double labelling with fluorescent dyes. Neurosci. Lett. 19: 125-130.

Innocenti, G. M. (1981) Growth and reshaping of axons in the establishment of visual callosal connections. Science 212: 824-827.

Itoh, K., M. Conley, and I. T. Diamond (1980) Ganglion cell projections to the superior colliculus, lateral geniculate, pretectum and ventral lateral geniculate in the cat. Soc. Neurosci. Abstr. 6: 347.

Ivy, G. O., and H. P. Killackey (1981) The ontogeny of distribution of callosal projection neurons in the rat parietal cortex. J. Comp. Neurol. 195: 367-389.

Jeffery, G., and V. H. Perry (1981) Evidence for ganglion cell death during development of the ipsilateral retinal projection in the rat. Dev. Brain Res. 2: 176-180.

Jeffery, G., A. Cowey, and H. G. J. M. Kuypers (1981) Bifurcating retinal ganglion cell axons in the rat, demonstrated by retrograde double labelling. Exp. Brain Res. 44: 34-40.

Kalil, R. (1978) Development of the dorsal lateral geniculate nucleus in the cat. J. Comp. Neurol. 182: 265-292.

Kanaseki, T., and J. M. Sprague (1974) Anatomical organization of pretectal nuclei and tectal laminae in the cat. J. Comp. Neurol. 158: 319-338.

Kelly, J. P., and C. D. Gilbert (1975) The projections of different morphological types of ganglion cells in the cat retina. J. Comp. Neurol. 163; 65-80.

Kliot, M., and C. J. Shatz (1981) Siamese cat: Prenatal development of the retinogeniculate pathway. Invest. Ophthalmol. Vis. Sci. Suppl. 20: 175.

Kuwabara, T., and T. A. Weidman (1974) Development of the prenatal rat retina. Invest. Ophthalmol. 13: 725-739.

Kuypers, H. G. J. M., C. E. Catsman-Berrevoets, and R. E.
Padt (1977) Retrograde axonal transport of fluorescent substances in the rat's forebrain. Neurosci. Lett. 6: 127-135.

Land, P. W., and R. D. Lund (1979) Development of the rat's uncrossed retinotectal pathway and its relation to plasticity studies. Science 205: 698-700.

Langer, T. L. (1975) Organization of cat superior colliculus: A Golgi and degeneration study. Anat. Rec. 181: 404.

Laties, A. M., and J. M. Sprague (1966) The projection of optic fibers to the visual centers in the cat. J. Comp. Neurol. 127: 35-70.

LeVay, S., and M. P.Stryker (1979) The development of ocular dominance columns in the cat. In Society for Neuroscience Symposia. Vol. 4: Aspects of Developmental Neurobiology, J. A. Ferrendelli, ed., pp. 83-98, Society for Neuroscience, Bethesda, MD.

Lund, R. D., and A. H. Bunt (1976) Prenatal development of central optic pathways in albino rats. J. Comp. Neurol. 165 . 247-264.

Magalhães-Castro, H. H., L. A. Murata, and B. MagalhãesCastro (1976) Cat retinal ganglion cells projecting to the superior colliculus as shown by the horseradish peroxidase method. Exp. Brain Res. 25: 541-549.

Mason, C. A. (1980) Postnatal development of retinogeniculate axon arbors in the kitten. Soc. Neurosci. Abstr. 6: 660 .

McLoon, S. C., and R. D. Lund (1980) Formation and loss of a normal ipsilateral retinofugal projection in developing chick. Soc. Neurosci. Abstr. 6: 617.

Mesulam, M. M. (1978) Tetramethyl benzidine for horseradish peroxidase neurohistochemistry: A non-carcinogenic blue reaction-product with superior sensitivity for visualizing neural afferents and efferents. J. Histochem. Cytochem. 26: 106-117.

Mize, R. R. (1981) Morphological identification of retinal synapses in the cat superior colliculus using quantitative electron microscope autoradiography. Invest. Ophthalmol. Vis. Sci. Suppl. 20: 185.

Northcutt, R. G. (1980) Retinal projections in the Australian lungfish. Brain Res. 185: 85-90.

Northcutt, R. G., and A. B. Butler (1976) Retinofugal pathways in the longnose gar Lepisosteus ossous (Linnaeus). J. Comp. Neurol. 166: 1-16.

Northcutt, R. G., and R. J. Przybylski (1973) Retinal projections in the lamprey Petromyzon marinus (L). Anat. Rec. 150: 400.

Northcutt, R. G., and J. C. Wathey (1980) Guitarfish possess ipsilateral as well as contralateral retinofugal projections. Neurosci. Lett. 20: 237-242.

O'Leary, J. L. (1940) A structural analysis of the lateral geniculate nucleus of the cat. J. Comp. Neurol. 73: 405-430.

Pollack, J. G., and T. L. Hickey (1979) The distribution of retino-collicular axon terminals in rhesus monkey. J. Comp. Neurol. 185: 587-602.

Rager, G., and U. Rager (1976) Generation and degeneration of retinal ganglion cells in the chicken. Exp. Brain Res. 25: $551-553$.

Rakic, P. (1974) Neurons in rhesus monkey visual cortex: Systematic relation between time of origin and eventual disposition. Science 183: 425-427.

Rakic, P. (1976) Differences in the time of origin and in the eventual distribution of neurons in areas 17 and 18 of the visual cortex in rhesus monkey. Exp. Brain Res. Suppl. 1: 244-248.

Rakic, P. (1977a) Prenatal development of the visual system in rhesus monkey. Philos. Trans. R. Soc. Lond. (Biol.) 278: 245-260.

Rakic, P. (1977b) Genesis of the dorsal lateral geniculate nucleus in the rhesus monkey: Site and time of origin, kinetics of proliferation, routes of migration and pattern of distribution of neurons. J. Comp. Neurol. 176: 23-52.

Ramón y Cajal, S. (1911) Histologie du Système Nerveux de l'Homme et d'est Vertébrès, Maloine, Paris. Reprinted (1955) 
by Consejo Superior de Investigaciones Cientificas, Madrid, Vol. 2, p. 373.

Sengelaub, D. R., and B. L. Finlay (1981) Early removal of one eye reduces normally occurring cell death in the remaining eye. Science 213: 573-574.

Shatz, C. J., and A. C. DiBerardino (1980) Prenatal development of the retinogeniculate pathway in the cat. Soc. Neurosci. Abstr. 6: 485.

Sidman, R. L. (1961) Histogenesis of mouse retina studied with thymidine- $\mathrm{H}^{3}$. In The Structure of the Eye, G. K. Smelser, ed., pp. 487-506, Academic Press, New York.

So, K -F. and G. E. Schneider (1978) Postnatal development of retinogeniculate projections in Syrian hamsters: An anterograde HRP study. Soc. Neurosci. Abstr. 4: 127.

Spear, P. D., D. C. Smith, and L. L. Williams (1977) Visual receptive-field properties of single neurons in cat's ventral lateral geniculate nucleus. J. Neurophysiol. 40: 390-409.

Sterling, P. (1973) Quantitative mapping with the electron microscope: Retinal terminals in the superior colliculus. Brain Res. 54: 347-354.

Stone, J. (1978) The number and distribution of ganglion cells in the cat's retina. J. Comp. Neurol. 180: 753-772.

Stone, J., and Y. Fukuda (1974) Properties of cat retinal ganglion cells: A comparison of W-cells with X-and Y-cells. J. Neurophysiol. 37: 722-748.

Stone, J., D. H. Rapaport, R. W. Williams, and L. M. Chalupa (1981) Uniformity of cell distribution in the ganglion cell layer of prenatal cat retina: Implications for mechanisms of retinal development. Dev. Brain Res. 2: 231-242.

Tigges, J., J. Ros, and M. Tigges (1977) An autoradiographic investigation of the subcortical visual system in chimpanzee. J. Comp. Neurol. 172: 367-380.

Wässle, H., and R. -B. Illing (1980) The retinal projection to the superior colliculus in the cat: A quantitative study with HRP. J. Comp. Neurol. 190: 333-356.

Williams, R. W., and L. M. Chalupa (1980) Projections of retinal ganglion cells in the fetal cat. Soc. Neurosci. Abstr. 6: 492.

Williams, R. W., and L. M. Chalupa (1981) Prenatal development of retinal projections to the midbrain of the cat. Invest. Ophthalmol. Vis. Sci. Suppl. 20: 74.

Wilson, M. E., and M. J. Toyne (1970) Retino-tectal and corticotectal projections in Macaca mulatta. Brain Res. 24: 395-406. 